D) Check for updates

Cite this: Food Funct., 2018, 9, 6381

\section{Effect of in vitro digestion on the functional properties of Psidium cattleianum Sabine (araçá), Butia odorata (Barb. Rodr.) Noblick (butiá) and Eugenia uniflora L. (pitanga) fruit extracts}

\author{
Juliana Vinholes, (D) *a Sofia F. Reis, (DD ${ }^{\mathrm{b}}$ Graciele Lemos, ${ }^{a}$ Rosa Lia Barbieri, (D) a \\ Victor de Freitas, (D) ${ }^{b}$ Rodrigo C. Franzon (D) ${ }^{a}$ and Márcia Vizzotto (D) *a
}

\begin{abstract}
Brazilian native fruits are reported to be promising sources of bioactive compounds; however their bioactivity depends on their stability along the digestive process. This study evaluated the $\alpha$-glucosidase inhibition, antioxidant activity and total phenolic content (TPC) stability of araçá, butiá and pitanga fruit extracts using an in vitro digestion model. Additionally, the individual phenolic compound recovery of the most stable and active extract was evaluated by HPLC-DAD-ESI-MS/MS. Overall, the antioxidant activity of all extracts decreased along the process. Araçá fruit extracts, at the end of digestion, showed $\alpha$-glucosidase inhibition values similar to their non-digested extracts and the highest TPC recovery (28\%). Recovery of individual phenolic compounds of red araçá fruit extract revealed a negative impact on the stability of ellagitannins. Araçá fruit extract seems to provide phenolic compounds with $\alpha$-glucosidase inhibitory properties after the gastrointestinal digestion, indicating their potential to be used in the control of type II diabetes.
\end{abstract}

Received 4th July 2018, Accepted 24th October 2018 DOI: $10.1039 / \mathrm{c} 8 \mathrm{fo} 01329 \mathrm{~b}$ rsc.li/food-function inhibitors interact with the $\alpha$-glucosidase enzyme and retard the absorption of carbohydrates and consequently suppress postprandial hyperglycaemia. ${ }^{5}$ During the past few years, several research groups have devoted their activities trying to find $\alpha$-glucosidase inhibitors in different natural resources. In this sense, different medicinal plants, vegetables, marine organisms and fruits as well as products derived from them have been studied. Among these natural resources, Brazilian native fruits seem to be promising $\alpha$-glucosidase inhibitor agents $^{6,7}$ and there are other species which have not been fully explored yet. Recently, we reported the potential of three Brazilian native fruits with commercial interest as inhibitors of $\alpha$-glucosidase, ${ }^{7}$ namely Psidium cattleianum Sabine (araçá), Butia odorata (Barb. Rodr. Noblick) (butiá) and Eugenia uniflora L. (pitanga) (Fig. 1).

Araçá, belonging to the Myrtaceae family, is known as Cattley guava, and also as strawberry or lemon guava depending on the peel colour (red or yellow). The fruit shape is ovoid to oblong with $2.2-5 \mathrm{~cm}$ of diameter weighing less than $20 \mathrm{~g}$, including a high number of seeds. ${ }^{8}$ Vitamin $\mathrm{C}$ and phenolic compounds, mainly epicatechin, gallic acid ${ }^{8}$ and hydrolysable ellagitannins, are the main constituents of araçá fruits. ${ }^{9,10}$ Butiá, from the Arecaceae family, can be ovoid to depressedglobose in shape, with a length average of $1.79 \mathrm{~cm}$ and a circumference of $2.68 \mathrm{~cm} .{ }^{11}$ The peel colour can range from yellow to red. Its pulp is sweet-acidic and is rich in fibres, provitamins $\mathrm{A}$ and $\mathrm{C}$, carotenoids and potassium. ${ }^{12}$ Pitanga
${ }^{a}$ Embrapa Clima Temperado, BR 392, KM 78, C. P. 403, CEP 96010-971, Pelotas, RS, Brazil. E-mail: julianarochavinholes@gmail.com, marcia.vizzotto@embrapa.br ${ }^{b}$ ICETA/REQUIMTE/LAQV, Departamento de Química e Bioquímica, Faculdade de Ciências da Universidade do Porto, Rua do Campo Alegre, 687, 4169-007 Porto, Portugal 


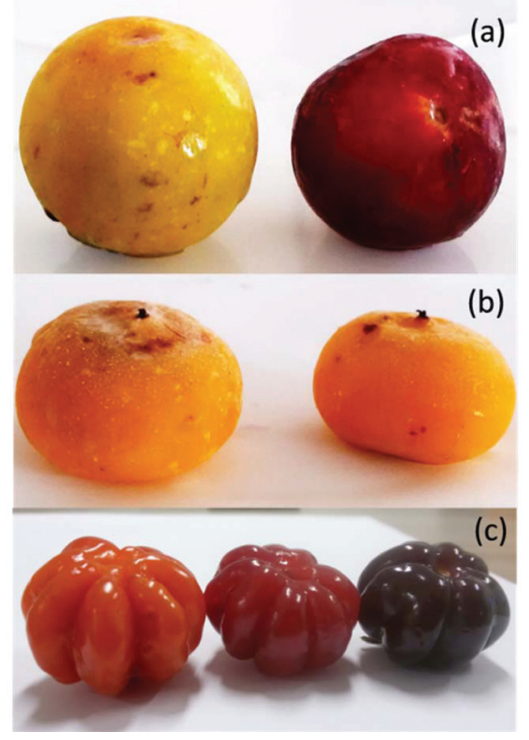

Fig. 1 Psidium cattleianum Sabine (araçá) (a), Butia odorata (Barb. Rodr. Noblick) (butiá) (b) and Eugenia uniflora L. (pitanga) (c).

(Brazilian cherry or Surinam cherry), from the Myrtaceae family, is considered a small fruit $(3 \mathrm{~cm}$ diameter $)$ and resembles a small pumpkin. ${ }^{13}$ The fruit colour ranges from orange to purple and fruits are described as exotic flavour with sweet and sour taste. Pitanga is a good source of carotenoids and also a good source of phenolic compounds, mainly anthocyanins and flavonoids. ${ }^{14}$ Among these three Brazilian native species, araçá stood out due to its high potential to inhibit the $\alpha$-glucosidase enzyme, followed by all pitanga fruits and in a less extent by butia fruit extract. ${ }^{7}$ Nevertheless, since the $\alpha$-glucosidase enzyme is mostly present in the intestine, the stability study of the bioactive compounds present in those extracts along the digestive process is of high concern since they can change significantly. ${ }^{15}$ In vitro digestion models have been widely used to study the stability of bioactive compounds. ${ }^{16}$ Moreover, these models are a tool to predict the bioavailability and absorption of fruit antioxidants in biological systems. ${ }^{17-21}$ Simulated in vitro digestion considering mouth, gastric and small intestine digestion is easy to run in any laboratory and such methods are an alternative to in vivo techniques (animal and human models) and have the advantage of being less expensive, faster and ethically superior. ${ }^{22}$

Considering the potential of these three Brazilian native fruits as inhibitors of $\alpha$-glucosidase, the primary goal of this study was to evaluate the changes in $\alpha$-glucosidase inhibition and antioxidant capacity of araçá, butiá and pitanga fruit extracts along an in vitro digestive model and assess the effect of each step on the recovery of total polyphenols. In addition, we also intended to identify the most stable and active extract and investigate the individual phenolic changes along the digestion using high-performance liquid chromatography coupled to a diode array detector and tandem mass spectrometry (HPLC-DAD-ESI-MS/MS).

\section{Materials and methods}

\subsection{Standards and reagents}

Reagents were purchased from different suppliers. Iron sulphate heptahydrate, salicylic acid, ethylenediaminetetraacetic acid disodium salt (EDTA-Na), chlorogenic acid, citric acid, quercetin-3-O-glucoside, ellagic acid, 2,2-diphenyl-1-picrylhydrazyl radical (DPPH'), sodium hydrogen carbonate $\left(\mathrm{NaHCO}_{3}\right)$, bile salts, phosphate buffer, pancreatin (from porcine pancreas, Enzyme Comission (EC) number: 232-468-9), pepsin (from porcine gastric mucosa, EC number: 232-629-3), $\alpha$-amylase (Type I-A from porcine pancreas, EC number: 3.2.1.1), $\alpha$-glucosidase (type I from baker's yeast EC number: 3.2.1.20) and 4-nitrophenyl $\alpha$-D-glucopyranoside (PNP-G) were obtained from Sigma-Aldrich (St Louis, MO, USA). Ethanol was purchased from Synth (Diadema, SP, Brazil), ascorbic acid, hydrochloric acid $(\mathrm{HCl})$ and hydrogen peroxide solution $(30 \%$ $\mathrm{w} / \mathrm{w}$ ) were from Impex (Diadema, SP, Brazil) and acetonitrile and formic acid were from Chem-Lab NV (Zedelgem, Belgium).

\subsection{Samples}

Samples of butiá (Butia odorata) were collected in two different locations in Rio Grande do Sul state, Southern Brazil: one sample from Herval and one from Santa Vitória do Palmar (SVP). Orange, red and purple-fleshed selections of pitanga fruits (E. uniflora), and yellow and red selections of araçá ( $P$. cattleianum) were obtained from the Active Germplasm Bank of native fruits from Southern Brazil at Embrapa Clima Temperado, Pelotas. All samples were harvested in 2015, between the months of March and April. A mixture of completely ripe fruits was sampled. Fruits were chosen based on the absence of visible injury and infections and selected depending on the colour and size before being frozen $\left(-20^{\circ} \mathrm{C}\right)$ until analysis.

\subsection{Preparation of fruit extracts}

The fruit extract was prepared from the edible portions of fruits: (i) skins and pulps of butiá and pitanga and (ii) skin, pulp and seeds of araçá. At least 10 fruits for each sample were thawed at room temperature and sliced. Individual fruit extracts were obtained for each sample by mixing $5 \mathrm{~g}$ of each fruit with $95 \%$ ethanol (at 1:4, w/v) using an Ultra-Turrax homogenizer (5 min) (Ika, Artur Nogueira, São Paulo, Brazil). Extracts were filtered and dried using a rotatory evaporator at $40{ }^{\circ} \mathrm{C}$. Extracts were prepared in triplicate and dissolved in ethanol/water $(3: 1 \mathrm{v} / \mathrm{v})$ to a concentration of $5.8 \mathrm{mg} \mathrm{mL}^{-1}$ and stored at $-20{ }^{\circ} \mathrm{C}$ until analysis. The concentration of the extracts used in this study was chosen based on their total polyphenol content ${ }^{7}$ and the intake of polyphenols reported for fruits. ${ }^{23}$

\subsection{In vitro simulated digestion}

The in vitro digestion procedure was carried out on butiá, pitanga and araçá extracts to evaluate their biological potential and recovery of the total phenolic compound content according to Gião et al. $(2012)^{24}$ with a few modifications. The 
method reproduced three physiological steps of the digestion process: $\alpha$-amylase digestion to simulate mouth conditions (mouth digesta); digestion with pepsin/ $\mathrm{HCl}$ to simulate gastric conditions (gastric digesta); and digestion with bile salts/pancreatin/ $/ \mathrm{NaHCO}_{3}$ to simulate small intestine conditions (intestinal digesta). Extracts were evaluated for each digestive process separately (mouth digesta, gastric digesta and intestinal digesta) and a total digestive process was also carried out (complete digesta).

2.4.1. Mouth digestion. An aliquot of $0.9 \mathrm{~mL}$ of each extract $\left(5.8 \mathrm{mg} \mathrm{mL}^{-1}\right)$ was diluted in $10 \mathrm{~mL}$ of distilled water and mixed with a freshly prepared $\alpha$-amylase solution $\left(0.60 \mathrm{~mL}, 100 \mathrm{mU} \mathrm{mL}^{-1}\right)$, and incubated at $37^{\circ} \mathrm{C}$ for $1 \mathrm{~min}$ in a water bath under shaking (200 rpm).

2.4.2. Gastric digestion. The gastric digestion was performed by adding $0.9 \mathrm{~mL}$ of each extract $\left(5.8 \mathrm{mg} \mathrm{mL} \mathrm{m}^{-1}\right)$ to $10 \mathrm{~mL}$ of distilled water, adjusting the $\mathrm{pH}$ to $2.0(\mathrm{HCl}, 1 \mathrm{M})$ and the mixture was incubated at $37^{\circ} \mathrm{C}$ for $1 \mathrm{~h}$ under shaking (130 rpm) with $0.5 \mathrm{~mL}$ of freshly prepared pepsin solution $\left(25 \mathrm{mg} \mathrm{mL}^{-1}\right.$ in $\left.0.1 \mathrm{M} \mathrm{HCl}\right)$.

2.4.3. Intestinal digestion. For the intestinal digestion, $0.9 \mathrm{~mL}$ of each extract $\left(5.8 \mathrm{mg} \mathrm{mL}^{-1}\right)$ was added to $10 \mathrm{~mL}$ of distilled water, and samples were adjusted to $\mathrm{pH} 6.0$ with $\mathrm{NaHCO}_{3}(1 \mathrm{M})$ before addition of $2.5 \mathrm{~mL}$ of freshly prepared pancreatin-bile salt solution $\left(2 \mathrm{~g} \mathrm{~L}^{-1}\right.$ of pancreatin plus $12 \mathrm{~g} \mathrm{~L}^{-1}$ of bile salts in $\left.\mathrm{NaHCO}_{3}(0.1 \mathrm{M})\right)$ and incubated for $1 \mathrm{~h}$ at $37^{\circ} \mathrm{C}$.

2.4.4. Complete digestion. $0.9 \mathrm{~mL}$ of each extract $(5.8$ $\mathrm{mg} \mathrm{mL} \mathrm{m}^{-1}$ ) was added to $10 \mathrm{~mL}$ of distilled water, mixed with a freshly prepared $\alpha$-amylase solution $\left(0.60 \mathrm{~mL}, 100 \mathrm{mU} \mathrm{mL}^{-1}\right)$, and incubated at $37{ }^{\circ} \mathrm{C}$ for $1 \mathrm{~min}$ in a water bath under shaking $(200 \mathrm{rpm})$. The $\mathrm{pH}$ was adjusted to $2.0(\mathrm{HCl}, 1 \mathrm{M})$ and the mixture was incubated at $37^{\circ} \mathrm{C}$ for $1 \mathrm{~h}$ under shaking (130 $\mathrm{rpm}$ ) with $0.5 \mathrm{~mL}$ of freshly prepared pepsin solution $\left(25 \mathrm{mg} \mathrm{mL} \mathrm{m}^{-1}\right.$ in $0.1 \mathrm{M} \mathrm{HCl}$ ). $\mathrm{pH}$ of samples was adjusted to 6.0 with $\mathrm{NaHCO}_{3}(1 \mathrm{M})$ before addition of $2.5 \mathrm{~mL}$ of freshly prepared pancreatin-bile salt solution $\left(2 \mathrm{~g} \mathrm{~L}^{-1}\right.$ of pancreatin plus $12 \mathrm{~g} \mathrm{~L}^{-1}$ of bile salts in $\left.\mathrm{NaHCO}_{3}(0.1 \mathrm{M})\right)$ and incubated for $1 \mathrm{~h}$ at $37^{\circ} \mathrm{C}$ and $45 \mathrm{rpm}$.

Enzymatic inactivation was carried out by dipping samples in water $\left(100{ }^{\circ} \mathrm{C}\right)$ for $1 \mathrm{~min}$. Samples were filtered through a $0.45 \mu \mathrm{m}$ membrane and frozen until analysis. Controls of the sample with adjusted $\mathrm{pH}$ for each step, in the absence of enzymes, were run in parallel (controls). One control was run for each extract $(n=3)$ and extracts with added enzymes were run in duplicate $(n=6)$. Activities and the chemical composition of the non-digested extracts were used for comparison considering the same final concentration of each digestive step.

\section{5. $\alpha$-Glucosidase inhibition and antioxidant activities along the digestive process}

2.5.1. General. $\alpha$-Glucosidase inhibition and antioxidant capacity of digested fruit extracts were determined spectrophotometrically using an Amersham, Modelo UV Vis Ultrospec3100 Pro Amersham Bioscience spectrophotometer. For each assay the percentage of inhibition $(I \%)$ was calculated using the following formulae:

$$
I(\%)=\frac{A_{\text {control }}-A_{\text {sample }}}{A_{\text {control }}} \times 100
$$

where $A_{\text {control }}$ is the absorbance of the control reaction (containing all reagents except the extract), and $A_{\text {sample }}$ is the absorbance of the tested extract in the reaction mixture. Assays were performed in triplicate and expressed as mean \pm standard error of the mean (SEM). The results were adjusted according to the dilution factor for each digestive step.

2.5.2. $\alpha$-Glucosidase inhibitory activity. The $\alpha$-glucosidase inhibitory activity of extracts was assessed using a procedure previously reported. ${ }^{7}$ The method consisted of mixing $20 \mu \mathrm{L}$ of the fruit extract or ethanol (control) with $100 \mu \mathrm{L}$ of PNP-G (3.25 mM, in phosphate buffer, pH 7.0). A volume of $100 \mu \mathrm{L}$ of enzyme $\left(9.37 \mathrm{U} \mathrm{mL}^{-1}\right.$ in phosphate buffer, $\left.\mathrm{pH} 7.0\right)$ was added to the vial to initiate the reaction and the mixture was incubated at $37{ }^{\circ} \mathrm{C}$ for $10 \mathrm{~min}$. After the addition of $600 \mu \mathrm{L}$ of $\mathrm{Na}_{2} \mathrm{CO}_{3}(1 \mathrm{M})$ to stop the reaction, the absorbance was measured at $405 \mathrm{~nm}$.

2.5.3. DPPH' scavenging activity. DPPH" scavenging activity was measured using a procedure previously reported. ${ }^{7}$ The reaction mixture consisted of $100 \mu \mathrm{L}$ of each extract or ethanol (control) and $1000 \mu \mathrm{L}$ of $\mathrm{DPPH}^{*}(0.6 \mathrm{mM}$, in methanol). The absorbance was measured at $515 \mathrm{~nm}$, after $30 \mathrm{~min}$ incubation in the dark at room temperature.

2.5.4. Hydroxyl radical scavenging activity. Hydroxyl radical scavenging activity was measured using a procedure previously reported. ${ }^{7}$ The reaction was initiated by mixing $750 \mu \mathrm{L}$ of salicylic acid ( $3 \mathrm{mM}$ ), $250 \mu \mathrm{L}$ of each extract or ethanol (control), $1100 \mu \mathrm{L}$ of iron sulphate heptahydrate solution $(8 \mathrm{mM}$, prepared in EDTA-Na $20 \mu \mathrm{M})$ and $500 \mu \mathrm{L}$ of $\mathrm{H}_{2} \mathrm{O}_{2}$ solution $(7 \mathrm{mM})$. The reaction mixture was mixed (vortex) and incubated for $30 \mathrm{~min}$ at $37^{\circ} \mathrm{C}$ and the absorbance was determined at $515 \mathrm{~nm}$.

\subsection{Phenolic compound determination, characterisation and recovery}

2.6.1. Total phenolic content. The total phenolic content (TPC) was measured according to the Folin-Ciocalteu method adapted from Swain and Hillis (1959). ${ }^{25}$ An aliquot $(50 \mu \mathrm{L})$ of each treatment and the control $(50 \mu \mathrm{L}$ of water) were mixed with $250 \mu \mathrm{L}$ of Folin-Ciocalteau reagent $(0.25 \mathrm{~N})$. Samples were incubated for $3 \mathrm{~min}$. After this reaction period, $500 \mu \mathrm{L}$ of $\mathrm{Na}_{2} \mathrm{CO}_{3}(1 \mathrm{~N})$ was added and the mixtures were incubated for $2 \mathrm{~h}$ at room temperature. Absorbance was read at $725 \mathrm{~nm}$, and the results were expressed as chlorogenic acid equivalents per millilitre of extract ( $\mu \mathrm{g}$ of CAE per $\mathrm{mL}$ of extract) using a chlorogenic acid $\left(0-0.4 \mathrm{mg} \mathrm{mL}^{-1}\right)$ standard curve. The results were adjusted according to the dilution factor for each digestive step.

2.6.2. Phenolic compound analysis of the red araça fruit extract by HPLC-DAD-ESI-MS/MS. Phenolic compounds from red araçá samples (non-digested and digested extracts) were extracted using solid phase extraction (SPE) $\mathrm{C}_{18}$ cartridges (Bond Elut, Agilent). The cartridge was loaded with $1 \mathrm{~mL}$ of 
the samples and cleaned-up with $1 \mathrm{~mL}$ of water. The phenolic fraction was eluted with $1 \mathrm{~mL}$ acidic methanol $(0.1 \% \mathrm{HCl})$. Samples were filtered using membranes of $0.45 \mu \mathrm{m}$ and subjected to HPLC-DAD-ESI-MS/MS analysis. Samples $(20 \mu \mathrm{L})$ were eluted on a RP18 (5 $\mu \mathrm{m}, 4.0 \mathrm{~mm}, 250 \mathrm{~mm}$, LiChrospher $\left.{ }^{\circledR}\right)$ at $0.5 \mathrm{~mL} \mathrm{~min}^{-1}$, column temperature at $29^{\circ} \mathrm{C}$, with a mobile phase consisting of water/formic acid (99.5:0.5, v/v) (solvent A) and acetonitrile/formic acid (99.5: 0.5, v/v) (solvent B) using the following gradient: $1-50 \%$ solvent $\mathrm{B}$ in $50 \mathrm{~min}, 50-99 \%$ solvent B over $2 \mathrm{~min}$ and kept for $3 \mathrm{~min}, 99-1 \%$ solvent B in $5 \mathrm{~min}$ and kept for an additional $5 \mathrm{~min} .{ }^{9}$ All samples were analysed by HPLC-DAD-ESI-MS/MS performed on a Finnigan Surveyor Plus HPLC system fitted with a PDA Plus detector, an auto-sampler Plus and an LC quaternary pump Plus coupled to a Finnigan LCQ Deca XP Plus mass detector equipped with an ESI source and an ion trap quadrupole. A mass spectrometer was operated in the negative ionisation mode for a mass range from $\mathrm{m} / \mathrm{z} 170$ to 1000 . Capillary temperature was set at $275^{\circ} \mathrm{C}$ and the capillary voltage at $4.5 \mathrm{kV}$. The red araçá extract composition was tentatively identified based on the compound elution order, retention time, and spectroscopy features (UVVisible and mass spectra) by comparison with data of chemical standards analysed under the same conditions. Data reported in the literature for Psidium species ${ }^{9,10,26}$ were also checked.

2.6.3. Phenolic compound quantification. For phenolic compound quantification, $20 \mu \mathrm{L}$ of non-digested and digested red araçá fruit extracts were analysed on an analytical HPLC unit (Thermo Scientific), using the same elution conditions described above. Detection was achieved with a Thermo Scientific diode array detector. Spectral data from all peaks were collected in the range of 190-800 $\mathrm{nm}$ and chromatograms were recorded at 280 and $340 \mathrm{~nm}$. The data were processed on Chromeleon Studio software (Thermo Scientific). Compound identification was performed by comparison of their elution order and UV-vis spectra with those of phenolic compounds identified by HPLC-DAD-ESI-MS/MS. Peak purity was checked by the software contrast facilities. Quantification of phenolic compounds was carried out by HPLC-DAD employing external calibration curves prepared with pure standards. Seven-point calibration curves were recorded employing citric acid (50-1500 $\left.\mu \mathrm{g} \mathrm{mL} \mathrm{m}^{-1}, r^{2}=0.9897\right)$, ellagic acid $\left(5-160 \mu \mathrm{g} \mathrm{mL}{ }^{-1}\right.$, $\left.r^{2}=0.9981\right)$ and quercetin $\left(1.5-48 \mu \mathrm{g} \mathrm{mL} \mathrm{m}^{-1}, r^{2}=0.9985\right)$. The samples were injected in triplicate and the peak areas were determined at $280 \mathrm{~nm}$. Results were expressed as $\mu \mathrm{g} \mathrm{mL} \mathrm{m}^{-1}$ of extract. The results were adjusted according to the dilution factor for each digestive step.

2.6.4 Phenolic compound recovery after in vitro digestion. Phenolic compound recovery (\%) was calculated as a percentage of the TPC released from the in vitro digestion process compared to the TPC of the sample, according to the formula: ${ }^{27}$

$$
\% \text { Recovery }=\frac{\text { PCDS }}{\text { PCS }} \times 100
$$

where PCDS is the total phenolic content of the in vitro digested sample (after in vitro digestion) and PCS is the total phenolic content of the non-digested sample (before in vitro digestion).

\subsection{Statistical analysis}

Statistical significance $(p<0.05)$ of the difference between the extract and the changes along the digestive process was evaluated by one-way analysis of variance (ANOVA) followed by Tukey's test using Graph Pad version 5.0. Correlation analysis was performed using the Analyset-it ${ }^{\circledR}$ application for the Microsoft Excel program.

\section{Results and discussion}

\subsection{Effect of in vitro digestion on $\alpha$-glucosidase inhibition}

In the present study, the $\alpha$-glucosidase inhibition of native fruit extracts was studied along the digestive process. Extracts were evaluated either for each step of the digestion process (mouth digesta, gastric digesta and intestinal digesta) as well as for the total sequential digestion (complete digesta), with the respective extract controls (no added enzymes and adjusted $\mathrm{pH})$. The non-digested extract was also evaluated. The $\alpha$-glucosidase inhibition for the non-digested extract varied from 28 to $87 \%$ (Table 1). Red and yellow araçá fruit extracts were the most active ones and butiá from SVP the least active. Results of $\alpha$-glucosidase inhibition for both butiá extracts and red and orange pitanga extracts at the oral phase (mouth digesta) were not significantly different compared to the inhibitory results for their non-digested extracts (Table 1). Other fruit extracts showed reductions of 13 to $35 \%$. At the oral phase, only the red araçá extract showed significant differences between the extract control and the digested sample, showing that the presence of the $\alpha$-amylase enzyme may have changed the extract composition increasing its activity.

The gastric phase reduces significantly the $\alpha$-glucosidase inhibitory properties of the majority of fruit extracts (14-64\%) compared to their non-digested extracts. This loss of activity could be due to physicochemical alterations of compounds present in these matrices (i.e. oxidation), interaction with other compounds (phenolic compounds and polysaccharides) and also precipitation of phenolic compounds and proteins with enzymes due to changes in the medium caused by the decrease in $\mathrm{pH}^{28,29}$ At this step, results of $\alpha$-glucosidase activity were lower for all gastric digestion extracts, except for the yellow araçá extract, compared to control gastric extracts, showing the negative influence of the addition of enzymes on extract activity. Following the intestinal digestion phase, no significant differences were found comparing the $\alpha$-glucosidase inhibition of the digested and non-digested araçá extracts and purple pitanga extract (Table 1). $\alpha$-Glucosidase inhibition of all extracts was increased at this step (28-76\%) comparatively to the previous step. Similar results were observed by Lee, Lee, Chung and Hur (2016), ${ }^{30}$ indicating that this digestive stage can be responsible for the change or release of bioactive compounds resulting in an increased inhibitory activity. In addition, intestine digestion of Butiá from Herval resulted in higher $\alpha$-glucosidase activity than its respective control extract. In contrast, low $\alpha$-glucosidase activity was observed for intestine digestion of 
Table $1 \alpha$-Glucosidase inhibition, $\mathrm{DPPH}^{*}$ and $\mathrm{OH}^{*}$ scavenging activities of araçá, butiá and pitanga fruit ethanolic extracts along the digestive process. Results are expressed by the mean value of three experiments performed in triplicate. Means without a common superscript are significantly different from each other concerning the same sample and assay $(p<0.05)$. Values within brackets refer to the coefficient of variation expressed in percentage

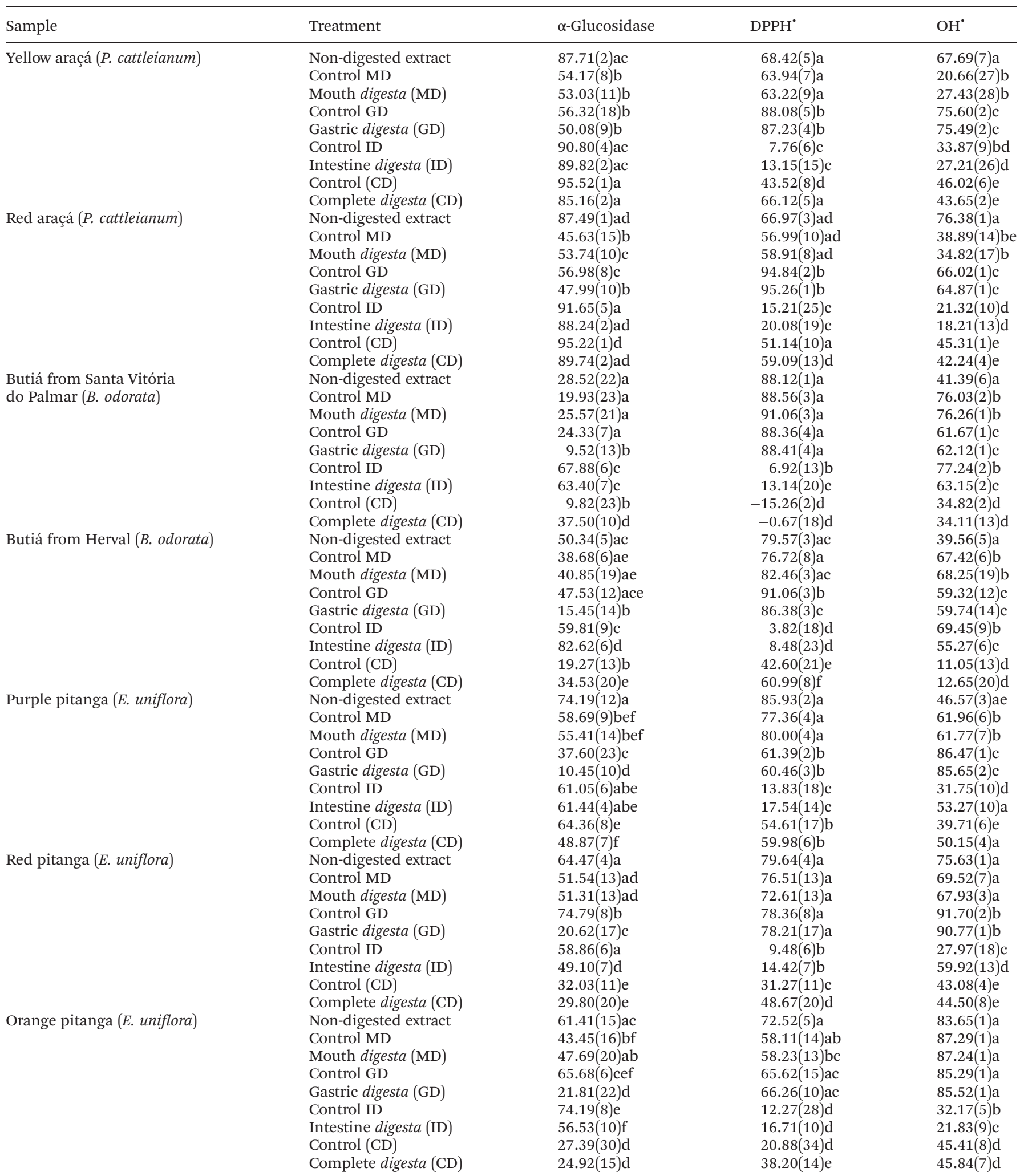


red and orange pitanga fruit extracts compared to their extract controls. Thus, the enzymes present at this phase seem to alter the composition of the samples with consequences on their action against the $\alpha$-glucosidase. No significant differences were found comparing the $\alpha$-glucosidase inhibition of araçá extracts at the complete digestion and their non-digested extracts. The $\alpha$-glucosidase inhibition of butiá from SVP (Table 1) increased 9\% comparatively to its non-digested extract, revealing the contribution of the intestinal digestion to its bioactivity. Other authors reported an increase of $20-38 \%$ in the $\alpha$-glucosidase inhibitory activity of different fruit juices after the digestive process. ${ }^{19}$ Decreases of 15 to $36 \%$ in $\alpha$-glucosidase inhibition were observed for butiá from Herval and all pitanga extracts. This loss is similar to the results obtained by other authors who reported 30 and $40 \%$ loss of activity against $\alpha$-glucosidase for Tribulus terrestris and chickpea, respectively, after the digestive process. ${ }^{27}$

\subsection{Effect of in vitro digestion on antioxidant activity}

The effect of the digestive process on $\mathrm{DPPH}^{*}$ scavenging activity of the Brazilian native fruit extracts can be observed in Table 1. Overall, the $\mathrm{DPPH}^{*}$ scavenging activity of extracts at the mouth digestion step was not significantly different from the activity of their non-digested extracts. The gastric phase increased the $\mathrm{DPPH}^{*}$ scavenging activity of yellow (22\%), red araça $(30 \%)$ and butiá from Herval extracts (7\%) compared to their non-digested extracts (Table 1). At the intestinal phase, the extract activity over $\mathrm{DPPH}^{*}$ was reduced by 69 to $97 \%$ compared with their non-digested extracts. The $\mathrm{DPPH}^{*}$ scavenging activity for araça at complete digestion was similar to their non-digested extracts. However, reductions in $\mathrm{DPPH}^{*}$ scavenging activity were observed for pitanga and butiá extracts, probably as a consequence of the reductions in activity observed for the intestinal digesta phase.

The literature concerning the influence of gastrointestinal digestion is divergent. Maqui berries were reported with a $75 \%$ reduction of $\mathrm{DPPH}^{*}$ scavenging activity after the digestive process, ${ }^{20}$ and the same behaviour was reported for blueberry and cherry wines, ${ }^{31}$ and for durian, nectarine, plum (sanhua) and red bayberry fruits. ${ }^{17}$ Nevertheless, an increase in the $\mathrm{DPPH}^{*}$ scavenging activity after gastrointestinal digestion compared to the initial phase was reported for pomegranate peel, ${ }^{32}$ and for fruits such as apple (red delicious), banana, cantaloupe, grapes (black, green, red and USA), grapefruit, litchi, loquat, mango (Hainan), mangosteen, orange, peach, pear (fragrant, honey, Hubei and royal), plum (green), pitaya (white pulp) and watermelon (red and yellow pulp). ${ }^{17}$ In addition, different commercial tea juices also showed increased $\mathrm{DPPH}^{\circ}$ scavenger activity after in vitro digestion. ${ }^{18}$ The variation in $\mathrm{DPPH}^{\circ}$ scavenger activity can be probably due to the matrix chemical changes that take place during the digestion process such as oxidation, and interactions with other compounds and enzymes, as previously mentioned.

The hydroxyl radical scavenger properties of extracts along the digestive process are presented in Table 1. Non-digested fruit extract scavenger activity over hydroxyl radicals ranged from 39 to $83 \%$. At the oral phase, reductions of 40 and $50 \%$ in activity were observed for red and yellow genotypes, respectively, when compared to non-digested extracts. In contrast, an increase of 20 and $30 \%$ in hydroxyl radical scavenging ability was observed for purple pitanga and butiá extracts, respectively. At this phase, the activity of red and orange pitanga extracts was not statistically different from their non-digested extracts. Yellow araçá, butiá and purple and red pitanga extracts showed an increased hydroxyl radical scavenging activity for the gastric phase compared to their non-digested extracts. On the other hand, orange pitanga extract scavenging ability was maintained and a decrease was observed for red araçá (Table 1). A similar decrease in hydroxyl radical scavenging was reported by Xiao, Huang, Chen and Li $(2014)^{33}$ for the extract of a medicinal plant (Radix isatidis). As far as we know, there is no literature about the action of fruit extracts on hydroxyl radicals along the digestive process. The intestinal step reduced the scavenging properties of araçá and pitanga fruit extracts by 20 to $60 \%$, respectively. A similar reduction of hydroxyl inhibitory activity (33\%) was also observed for the Radix isatidis extract after simulated gastrointestinal digestion. $^{33}$ On the other hand, both butiá extracts showed increased activity with values of 15 and $36 \%$ (Table 1). The complete digestion showed that the extract scavenging properties were reduced when compared to their non-digested extract results.

\subsection{Relevance of the total phenolic content in $\alpha$-glucosidase inhibition and antioxidant activity}

Phenolic compounds constitute a phytochemical group with different biological properties, including the $\alpha$-glucosidase inhibitory activity. It is well established by several studies that the TPC of a matrix gives an idea on how rich this product is in antioxidants since these parameters are closely related. The TPC of fruit extracts was determined along the digestive process (Table 2) in order to relate the enzymatic inhibition and antioxidant activity of each extract analysed with possible changes in the chemical composition. As can be observed in Table 2, the TPC in the extracts varied from 2268.82 to 3970.69 $\pm 1.1 \mu \mathrm{g}$ CAE per $\mathrm{mL}$ of extract.

A significant decrease in the TPC (1.9 to 3.5 fold) was observed for the majority of mouth digestion samples compared to their non-digested extracts, with the exception of butiá from Herval with a TPC recovery of almost $100 \%$. These results are in accordance with the decrease in inhibitory activity observed over the enzyme for araça and pitanga fruit extracts (Table 1). A positive correlation was observed for the TPC and the oral phase (Table 3). Following the gastric phase of in vitro digestion, red araçá and both butiá fruit extracts (Table 2) showed the highest TPC recovery (30 to 59\%). The TPC increases for yellow and red araça extracts when compared to the previous step, and this fact can be attributed to a decrease in the $\mathrm{pH}$ of extracts after the incubation at $\mathrm{pH} 2.0$, which may favour the recovery of some compounds. ${ }^{34}$ So far, this increase does not result in increased activity over the 
Table 2 Total phenolic content (TPC) recovery of araçá, butiá and pitanga fruit ethanolic extracts along the digestive process. Results are expressed by the mean value of three experiments performed in triplicate. Means without a common superscript are significantly different from each other concerning the same sample $(p<0.05)$

\begin{tabular}{llll}
\hline Sample & Treatment & TPC Recovery
\end{tabular}

Yellow araçá (P. cattleianum)

Red araçá (P. cattleianum)

Butiá from Santa Vitória

do Palmar (B. odorata)

Butiá from Herval (B. odorata)

Purple pitanga (E. uniflora)

Red pitanga (E. uniflora)

Orange pitanga (E. uniflora)
Non-digested extract

Control MD

Mouth digesta (MD)

Control GD

Gastric digesta (GD)

Control ID

Intestine digesta (ID)

Control (CD)

Complete digesta (CD)

Non-digested extract

Control MD

Mouth digesta (MD)

Control GD

Gastric digesta (GD)

Control ID

Intestine digesta (ID)

Control (CD)

Complete digesta (CD)

Non-digested extract

Control MD

Mouth digesta (MD)

Control GD

Gastric digesta (GD)

Control ID

Intestine digesta (ID)

Control (CD)

Complete digesta (CD)

Non-digested extract

Control MD

Mouth digesta (MD)

Control GD

Gastric digesta (GD)

Control ID

Intestine digesta (ID)

Control (CD)

Complete digesta (CD)

Non-digested extract

Control MD

Mouth digesta (MD)

Control GD

Gastric digesta (GD)

Control ID

Intestine digesta (ID)

Control (CD)

Complete digesta (CD)

Non-digested extract

Control MD

Mouth digesta (MD)

Control GD

Gastric digesta (GD)

Control ID

Intestine digesta (ID)

Control (CD)

Complete digesta (CD)

Non-digested extract

Control MD

Mouth digesta (MD)

Control GD

Gastric digesta (GD)

Control ID

Intestine digesta (ID)

Control (CD)

Complete digesta (CD) 2671.72(5)a

784.91(19)b

812.08(12)b

1244.59(4)c

1144.93(11)c

667.14(19)d

830.05(12)b

939.26(2)b

809.90(10)b

2698.90(2)a

926.44(15)b

868.15(18)b

1569.82(10)c

1590.45(9)c

$725.20(13) d$

789.76(15)d

1105.03(2)b

957.71(11)b

2393.09(11)a

1293.13(4)b

1361.82(5)b

1275.17(12)b

1399.20(5)b

446.08(11)c

737.99(12)d

248.76(13)e

399.22(16)ce

2398.12(10)a

2301.83(7)a

2375.86(5)a

1288.28(9)b

1148.96(7)b

191.24(17)c

433.50(19)d

225.52(12)cde

408.22(12)e

3970.69(7)a

1610.60(4)b

$1614.24(5) \mathrm{b}$

1228.09(12)c

1294.83(14)c

775.19(7)de

999.46(16)e

697.43(12)d

624.88(13)d

2268.82(7)a

957.95(8)b

811.12(10)bc

909.17(12)b

967.90(9)c

476.59(16)d

612.34(15)de

428.61(10)e

450.74(13)d

2338.72(6)a

918.88(15)b

935.62(16)b

708.21(16)bc

791.94(19)b

241.48(20)d

626.41(18)c

$370.45(3) d$

$494.87(15) d$
29

30

47

43

20

27

29

28

34

59

59

23

29

28

54

57

54

59

16

24

7

13

96

99

54

48

15

41

41

31

33

17

22

13

12

36

36

40

43

17

23

15

15

39

39

30

34

9

23

13

15 
Table 3 Correlation between the total phenolic content (TPC) recovery and bioactivities ( $\alpha$-glucosidase inhibition, DPPH and hydroxyl radicals scavenging activity) after each step (oral (MD), gastric (GD), intestinal (ID) and complete $(C D)$ ) of in vitro digestion

TPC

\begin{tabular}{lrrrrr}
\cline { 2 - 6 } Inhibition assay & \multicolumn{1}{c}{ ND } & \multicolumn{1}{c}{ MD } & \multicolumn{1}{c}{ GD } & \multicolumn{1}{c}{ ID } & CD \\
\hline$\alpha$-Glucosidase & -0.735 & -0.360 & 0.211 & 0.091 & 0.980 \\
DPPH $^{\circ}$ & 0.258 & 0.668 & 0.535 & 0.708 & 0.525 \\
Hydroxyl radicals & -0.736 & 0.359 & -0.669 & -0.249 & 0.340
\end{tabular}

enzyme but may have influenced the scavenging of $\mathrm{DPPH}^{\bullet}$ and hydroxyl radicals (Table 1 ).

It can also be noted that the TPC decreases for butiá from Herval, purple and orange pitanga extracts, and was maintained for butiá SVP and red pitanga extracts. For these extracts, it seems that the $\mathrm{pH}$ influences the stability of the compound resulting in a decrease of enzymatic inhibition. This fact was observed mainly for gastric digesta, which also changed negatively the antioxidant activity for purple pitanga $\left(\mathrm{DPPH}^{\circ}\right)$ and butiá (hydroxyl radicals) fruit extracts. At this phase, the TPC does not vary significantly between the gastric digesta treatments compared to their controls among the same samples.

At the intestinal phase, all extracts showed significant lower TPC recoveries than the previous phases varying from 5.5 to $26.6 \%$. No correlation was found between TPC and the increased $\alpha$-glucosidase inhibition observed for araçá and butia fruit extracts and TPC and the hydroxyl radical inhibition for the butia extract (Tables 1 and 2). However, as previously stated, changes in the chemical structures may occur, leading to compounds with increased inhibitory activity. ${ }^{30}$ Nevertheless, this decrease had negative consequences on scavenging of hydroxyl radicals of yellow and red araçá and red and orange pitanga fruit extracts and also for $\mathrm{DPPH}^{\circ}$ scavenging of all samples (Tables 1 and 2). Although a decrease in activity was observed for $\mathrm{DPPH}^{*}$ scavenging, a positive correlation $\left(r^{2} 0.708\right)$ with the TPC was observed (Table 3$)$.

Different authors showed that phenolic compounds are sensitive to mild alkaline conditions, suggesting that after intestinal digestion structural changes may occur forming compounds with different chemical properties. ${ }^{17}$ Anthocyanins and ellagitannins are the main groups of phenolic compounds affected by the alkaline conditions. ${ }^{21,35}$ Purple and red pitanga fruit extracts are rich in anthocyanins with values reported of $450.4 \pm 36.5$ and $60.1 \pm 5.3 \mathrm{mg}$ equivalents of cyanidin-3-glucoside per $100 \mathrm{~g}$ fresh weight, while the red araçá fruit extract is also composed of anthocyanins but in much smaller quantities $(29.3 \pm 1.4 \mathrm{mg}$ equivalents of cyanidin-3-glucoside per $100 \mathrm{~g}$ fresh weight). ${ }^{7}$ Araçá fruit extracts are reported to contain a large group of hydrolysable ellagitannins, ${ }^{9,10}$ which are hydrolysed, deprotonated and oxidised under alkaline conditions. $^{35,36}$ Considering the complete digestion, the in vitro digestion model carried out sequentially, recoveries varied from 7.3 to $29.4 \%$ (Table 2 ). At this phase, araçá fruit extracts were those with the highest percentage of recovered phenolic compounds (almost 30\%), followed by red and orange pitanga $(\sim 15 \%)$, butiá $(\sim 13 \%)$ and purple pitanga (12\%) fruit extracts.

It can be also observed that the TPC of digested araçá extracts was 3 fold lower than that of the respective nondigested extract, while for the other fruit extracts TPC values were 5 to 8 fold lowest. In fact, the TPC of araçá extracts did not change in comparison with the first digestion step (mouth) but showed higher inhibitory activity than their nondigested extracts. These results are supported by the correlation analysis between the biological activities and the TPC presented in Table 3. A high positive correlation $\left(r^{2} 0.980\right)$ was observed for $\alpha$-glucosidase inhibition and the TPC for the complete digesta, while low correlations were found for oral, gastric and intestinal digesta and $\mathrm{DPPH}^{*}$ scavenging. No correlation was observed between the TPC and hydroxyl radical scavenging. Since the red araçá fruit extract at the end of digestion showed the highest $\alpha$-glucosidase inhibition among the extracts studied, its individual phenolic composition along the digestive process was studied by HPLC-DAD-ESI-MS/MS.

\subsection{Effect of in vitro digestion on the recovery of phenolic compounds of the red araçá fruit extract}

The recovery of phenolic compounds present in the red araça fruit extract (the most stable and active extract concerning $\alpha$-glucosidase inhibition) was evaluated along the digestive process by HPLC-DAD and compounds were identified by HPLC-DAD-ESI-MS/MS. The retention times, UV and mass spectral characteristics and concentration of phenolic compounds present in the red araçá fruit extract are specified in Table 4.

The simulated in vitro digestion of the red araçá fruit extract leads to qualitative and quantitative differences which might be due to the degradation of compounds upon the effect of digestive enzymes and $\mathrm{pH}^{37}$ Recovery of phenolic compounds decreased significantly for mouth digesta (66\%) compared to the non-digested extract. At this step, the concentration of citric acid (compound 1) did not change compared to the non-digested extract. Recovery of flavonoids and ellagitannins decreased 18 to $29 \%$ and 45 to $100 \%$, respectively. Ellagitannin reduction may be due to their hydrolysis. ${ }^{36}$ Nevertheless, the recovery of HHDP-glucose increased 34\%, probably by hydrolysis of compounds containing the HHDPglucose unit (compounds 5, 8-12 and 14) as described in ref. 35. At the gastric phase, the total content of phenolic compounds decreased by $77 \%$. At this phase, the content of HHDP-glucose (compound 2) has also increased compared with the non-digested extract caused probably by the acidic pH. Intestinal digesta had the most negative impact on phenolic compound recoveries resulting in just 2\%. Citric acid (23\%) was the compound with highest values at this step. In addition, three ellagitannins (compounds 4, 10 and 11) and one flavonoid (compound 21) were quantified.

Complete digesta confirms the changes in phenolic compound recovery observed along the individual steps. Citric acid was the compound with highest recovery (49\%) at this step. 
Table 4 Retention time (RT), UV and mass spectrometric data, quantification and recovery (R) of phenolic compounds in the red araçá fruit extract after in vitro simulated digestion. Recovery is expressed in percentage regarding the initial phenolic content in the non-digested extract recovered after each step, mouth, stomach, intestine and complete digestions

\begin{tabular}{|c|c|c|c|c|c|c|c|c|c|c|c|c|c|c|}
\hline \multirow[b]{2}{*}{ No. } & \multirow[b]{2}{*}{ RT } & \multirow[b]{2}{*}{ Compounds } & \multirow[b]{2}{*}{$\begin{array}{l}\text { UV } \\
(\mathrm{nm})\end{array}$} & \multirow[b]{2}{*}[\mathrm{M}-\mathrm{H}]{$^{-}$} & \multirow[b]{2}{*}{$\begin{array}{l}\text { Fragments } \\
\qquad \mathrm{m} / \mathrm{z}\end{array}$} & \multicolumn{9}{|c|}{ Concentration in $\mu \mathrm{g} \mathrm{mL}^{-1}$ of extract } \\
\hline & & & & & & ND & MD & $\begin{array}{l}\mathrm{R} \\
(\%)\end{array}$ & GD & $\begin{array}{c}\mathrm{R} \\
(\%)\end{array}$ & ID & $\begin{array}{c}\mathrm{R} \\
(\%)\end{array}$ & $\mathrm{CD}$ & $\begin{array}{c}\mathrm{R} \\
(\%)\end{array}$ \\
\hline \multicolumn{15}{|c|}{ Organic acid ${ }^{1}$} \\
\hline 1 & 10.5 & Citric $\operatorname{acid}^{a}$ & 277 & 191 & $\begin{array}{l}\operatorname{MS}^{2}[191]: \mathbf{1 7 3} \\
111\end{array}$ & $2.30(1)$ & $2.75(28)$ & 119 & $1.95(12)$ & 85 & $0.52(12)$ & 23 & $1.12(15)$ & 49 \\
\hline \multicolumn{15}{|c|}{ Ellagitanins ${ }^{2}$} \\
\hline 2 & 15.9 & HHDP-glc ${ }^{b, c}$ & 259,285 & 481 & $\begin{array}{l}\operatorname{MS}^{2}[481]: 463 \\
319,301 \\
\operatorname{MS}^{3}[319]: 301\end{array}$ & 7.53(11) & $10.51(4)$ & 139 & $14.95(2)$ & 198 & & & & \\
\hline 3 & 16.9 & $\begin{array}{l}\text { Unknown } \\
\text { compound }\end{array}$ & 265,280 & 977 & $\begin{array}{l}\operatorname{MS}^{2}[977]: 932, \\
860,803,581\end{array}$ & $18.49(5)$ & $9.57(8)^{* * *}$ & 52 & $2.06(6)$ & 11 & & & & \\
\hline 4 & 17.0 & $\begin{array}{l}\text { Unknown } \\
\text { compound }\end{array}$ & 265,280 & 977 & $\begin{array}{l}\mathrm{MS}^{2}[977]: \mathbf{9 3 2} \\
915,870,569\end{array}$ & $32.31(3)$ & $16.75(1)^{* * *}$ & 52 & $17.81(1)^{* * *}$ & 55 & $1.64(1)$ & 5 & $5.54(3)^{* * *}$ & 17 \\
\hline 5 & 17.9 & di-HHDP-glc ${ }^{c, d}$ & 259,285 & 783 & $\begin{array}{l}\mathrm{MS}^{2}[783]: 481 \\
301,275 \\
\mathrm{MS}^{3}[301]: 257\end{array}$ & $24.46(1)$ & $11.82(4)^{* * *}$ & 48 & $3.68(6)^{* * *}$ & 15 & & & & \\
\hline 6 & 18.7 & $\begin{array}{l}\text { Castalagin/ } \\
\text { Vescalagin isomer }^{b}\end{array}$ & 259,282 & 933 & $\begin{array}{l}\mathrm{MS}^{2}[933]: 889 \\
631,569\end{array}$ & $57.19(1)$ & $32.36(1)^{* * *}$ & 57 & $11.62(2)^{* * *}$ & 20 & & & & \\
\hline 7 & 19.2 & $\begin{array}{l}\text { Castalagin/ } \\
\text { Vescalagin isomer }^{b}\end{array}$ & 259,282 & 933 & $\begin{array}{l}\mathrm{MS}^{2}[933]: 631 \\
451\end{array}$ & $24.38(10)$ & $16.65(2)^{* *}$ & 68 & $6.21(6)^{* * *}$ & 25 & & & & \\
\hline 8 & 19.5 & $\begin{array}{l}\text { Trisgalloyl } \\
\text { HHDP-glc isomer }^{b}\end{array}$ & 259,283 & 951 & $\begin{array}{l}\operatorname{MS}^{2}[951]: \mathbf{9 0 6} \\
605 \\
\operatorname{MS}^{3}[906]: ~ 783 \\
763,744,605\end{array}$ & $72.31(4)$ & $44.05(4)^{* * *}$ & 61 & $13.34(3)^{* * *}$ & 18 & & & & \\
\hline 9 & 19.8 & $\begin{array}{l}\text { Trisgalloyl } \\
\text { HHDP-glc isomer }^{b}\end{array}$ & 259,280 & 951 & $\begin{array}{l}\mathrm{MS}^{2}[951]: 906 \\
783,605\end{array}$ & $41.86(4)$ & $24.87(2)^{* * *}$ & 59 & $16.52(8)^{* * *}$ & 39 & & & & \\
\hline 10 & 20.7 & $\begin{array}{l}\text { Trisgalloyl } \\
\text { HHDP-glc isomer }^{b}\end{array}$ & 277 & 951 & $\begin{array}{l}\operatorname{MS}^{2}[951]: ~ 906 \\
783,605 \\
\operatorname{MS}^{3}[906]: ~ 783 \\
763,744,605\end{array}$ & $32.38(9)$ & $50.56(2)^{*}$ & 80 & $9.72(1)^{* * *}$ & 30 & $0.60(3)^{* * *}$ & 2 & $2.64(2)^{* * *}$ & 8 \\
\hline 11 & 21.2 & $\begin{array}{l}\text { Trisgalloyl } \\
\text { HHDP-glc isomer }^{b}\end{array}$ & 274 & 951 & $\mathrm{MS}^{2}[951]: 906$ & $41.80(1)$ & $23.28(5)^{* * *}$ & 56 & $9.60(1)^{* * *}$ & 23 & $1.91(3)^{* * *}$ & 5 & $1.93(2)^{* * *}$ & 5 \\
\hline 12 & 21.9 & $\begin{array}{l}\text { Galloyl-bis- } \\
\text { HHDP-glc }\end{array}$ & 280 & 935 & $\begin{array}{l}\operatorname{MS}^{2}[935]: \mathbf{6 3 3} \\
571,301 \\
\operatorname{MS}^{3}[633]: \mathbf{6 1 5} \\
480,329,365\end{array}$ & $76.44(3)$ & $50.61(5)^{* * *}$ & 66 & $16.78(5)^{* * *}$ & 22 & & & $6.23(4)^{* * *}$ & 8 \\
\hline 13 & 22.6 & HHDP-glc isomer ${ }^{b, c}$ & & 481 & $\begin{array}{l}\operatorname{MS}^{2}[481]: 463 \\
319,301 \\
\operatorname{MS}^{3}[319]: 301\end{array}$ & $112.54(4)$ & $67.16(1)^{* * *}$ & 60 & $28.93(3)^{* * *}$ & 26 & & & & \\
\hline 14 & 23.3 & $\begin{array}{l}\text { Galloyl-bis- } \\
\text { HHDP-glc isomer }\end{array}$ & 280 & 935 & $\begin{array}{l}\operatorname{MS}^{2}[935]: \mathbf{6 3 3} \\
419,329,301\end{array}$ & $53.30(6)$ & $31.70(5)^{* * *}$ & 59 & $7.75(3)^{* * *}$ & 15 & & & & \\
\hline \multicolumn{15}{|c|}{ Flavonoids ${ }^{3}$} \\
\hline 15 & 24.6 & $\begin{array}{l}\text { Taxifolin } \\
\text { hexoside }^{c}\end{array}$ & 286,349 & 465 & $\begin{array}{l}\mathrm{MS}^{2}[465]: \mathbf{4 3 7} \\
303,275,190 \\
\mathrm{MS}^{3}[437]: 275\end{array}$ & $1.32(4)$ & $0.95(4)$ & 72 & $0.32(5)^{* * *}$ & 24 & $0.10(1)^{* * *}$ & 7 & $0.08(1)$ & 6 \\
\hline 16 & 30.7 & $\begin{array}{l}\text { Quercetin- } \\
\text { glucoronide }^{d}\end{array}$ & 289,355 & 477 & $\mathrm{MS}^{2}[477]: 301$ & $1.29(1)$ & $0.91(13)$ & 70 & $0.20(6)^{* * *}$ & 16 & & & $0.17(2)$ & 13 \\
\hline 17 & 33.2 & $\begin{array}{l}\text { Eriodictyol } \\
\text { hexoside }^{c}\end{array}$ & 295,343 & 449 & $\begin{array}{l}\mathrm{MS}^{2}[449]: \mathbf{2 8 7} \\
\mathrm{MS}^{3}[287]: 269 \\
\mathbf{1 8 1}, 167,153\end{array}$ & $0.67(4)$ & $0.46(8)$ & 68 & $0.13(9)^{* * *}$ & 19 & & & $0.11(1)$ & 16 \\
\hline & & Total & & & & 674.49(4) & $447.24(6)^{* * *}$ & 66 & $154.25(11)^{* * *}$ & 23 & $12.34(5)^{* * *}$ & 2 & $32.79(4)^{* * *}$ & 5 \\
\hline
\end{tabular}

Non-digested extract (ND), mouth digesta (MD), gastric digesta (GD), intestinal digesta (ID), and complete digesta (CD). The most abundant fragment is shown in boldface. ${ }^{a}$ Identified with an authentic standard. ${ }^{b}$ Identified based on ref. $26 .{ }^{c}$ Identified based on ref. $10 .{ }^{d}$ Identified based on ref. 9. Values within brackets refer to the coefficient of variation. Significance differences were compared with the concentration of the non-digested extract ${ }^{*} P<0.05$, ${ }^{* *} P<0.01,{ }^{* *} P<0.001 .{ }^{1}$ Quantified by citric acid. ${ }^{2}$ Quantified by ellagic acid. ${ }^{3}$ Quantified by quercetin-3-O-glucoside.

Five ellagitannins (compounds 4, 10, 11, 12 and 13) and all flavonoids were also present with recoveries ranging from 5 to $17 \%$. The loss of ellagitannins was not followed by the appearance of ellagic and gallic acid as reported by other authors. ${ }^{36}$ This is probably due to the mild alkaline conditions used in the intestinal phase resulting in low concentrations of ellagic and gallic acid ${ }^{35}$ possibly lost in the purification step $\left(\mathrm{C}_{18}\right.$ cartridge $)$ used in the experimental conditions.
Concerning citric acid, there are no data reporting its $\alpha$-glucosidase inhibition properties. However, its oral administration to a type 1 diabetes model (streptozotocin-induced diabetic rats) delayed the development of cataracts, inhibited the accumulation of advanced glycation end products, and protected against albuminuria and ketosis without affecting blood glucose concentration. ${ }^{38}$ Moreover, different authors have reported the $\alpha$-glucosidase inhibition properties of ellagitan- 
nins. ${ }^{36,39}$ Losses in the concentration of these compounds were also observed for the pomegranate extract under simulated in vitro digestion and the extract still retained high $\alpha$-glucosidase inhibitory activity, ${ }^{36}$ similar to the result obtained for the red araçá fruit extract in the present study. Authors suggested that the hydrolysis of ellagitannins can release compounds with high activity over $\alpha$-glucosidase, and they related the activity to two main ellagitannins, punicalin and punicalagin. ${ }^{36}$

Although we could not observe such correlation, we can suggest that the red araçá fruit extract $\alpha$-glucosidase inhibitory activity might be due to the presence of ellagitannins and to new compounds with high activity not detected under the experimental conditions used in this work. The $\alpha$-glucosidase inhibitory activity for taxifolin-hexoside and eriodictyol is unknown, whereas quercetin-glucuronide was identified in the most active fractions of Geoffroea decorticans, a native fruit from Chile. ${ }^{40}$

\section{Conclusions}

The present study reports the changes in the $\alpha$-glucosidase inhibition and antioxidant activity of araçá, butiá and pitanga fruit extracts under simulated gastrointestinal digestion. This study provides, as far as we know, the first measurement of stability and recovery of bioactive compounds present in these native fruits. Araçá fruit extracts stood out due to their highest $\alpha$-glucosidase inhibition after the in vitro digestion, which was in accordance with their highest TPC recovery. HPLC-DAD-ESI-MS/MS analysis of the red araçá fruit extract revealed that only $5 \%$ of the identified compounds were available and ellagitannins were those most affected by the digestion. Ellagitannin hydrolysis can be responsible for the formation of compounds, not detected under the experimental conditions, with high $\alpha$-glucosidase inhibitory activity. Araçá fruit extracts can be therefore promising therapeutic agents for type II diabetes. Nevertheless, additional in vitro and in vivo experiments are required to prove the efficacy of these extracts regarding the diabetes pathology.

\section{Conflicts of interest}

There are no conflicts to declare.

\section{Acknowledgements}

This work was supported by National Council for Scientific and Technological Development (CNPq), Brazil, [process number 400201/2014-3, grant number 313712/2014-0].

\section{References}

1 M. N. Beidokhti and A. K. Jäger, J. Ethnopharmacol., 2017, 201, 26-41.
2 WHO, Diabetes, 2017. Retrieved September 15, 2017 from: http://www.who.int/mediacentre/factsheets/fs312/en/.

3 Y. Chen, F. Wu, E. Saito, Y. Lin, M. Song, H. N. Luu, P. C. Gupta, N. Sawada, A. Tamakoshi, X.-O. Shu, W.-P. Koh, Y.-B. Xiang, Y. Tomata, K. Sugiyama, S. K. Park, K. Matsuo, C. Nagata, Y. Sugawara, Y.-L. Qiao, S.-L. You, R. Wang, M.-H. Shin, W.-H. Pan, M. S. Pednekar, S. Tsugane, H. Cai, J.-M. Yuan, Y.-T. Gao, I. Tsuji, S. Kanemura, H. Ito, K. Wada, Y.-O. Ahn, K.-Y. Yoo, H. Ahsan, K. S. Chia, P. Boffetta, W. Zheng, M. Inoue, D. Kang and J. D. Potter, Diabetologia, 2017, 60, 1022-1032.

4 M. K. Song, D. S. Bischoff, A. M. Song, K. Uyemura and D. T. Yamaguchi, BBA Clin., 2016, 7, 41-54.

5 D.-Q. Li, Z.-M. Qian and S.-P. Li, J. Agric. Food Chem., 2010, 11, 6608-6613.

6 A. E. D. S. S. Gonçalves, F. M. Lajolo and M. I. Genovese, J. Agric. Food Chem., 2010, 58, 4666-4674.

7 J. Vinholes, G. Lemos, R. L. Barbieri, R. C. Franzon and M. Vizzotto, Food Biosci., 2017, 19, 92-100.

8 E. S. Pereira, J. Vinholes, R. C. Franzon, G. Dalmazo, M. Vizzotto and L. Nora, Food Chem., 2018, 258, 95-103.

9 A. B. Ribeiro, R. C. Chisté, M. Freitas, A. F. Da Silva, J. V. Visentainer and E. Fernandes, Food Chem., 2014, 165, 140-148.

10 N. A. Silva, E. Rodrigues, A. Z. Mercadante and V. V. Rosso, J. Agric. Food Chem., 2014, 62, 5072-5084.

11 C. Mistura, R. Barbieri, C. Castro, S. Padulosi and A. Alercia, Plant Genet. Resour., 2016, 14, 35-40.

12 G. T. Beskow, J. F. Hoffmann, A. M. Teixeira, J. C. Fachinello, F. C. Chaves and C. V. Rombaldi, Food Chem., 2014, 172, 699-704.

13 G. B. Celli, A. B. Pereira-Netto and T. Beta, Food Res. Int., 2011, 44, 2442-2451.

14 C. C. Denardin, G. E. Hirsch, R. F. da Rocha, M. Vizzotto, A. T. Henriques, J. C. F. Moreira, F. T. C. R. Guma and T. Emanuelli, J. Food Drug Anal., 2015, 23, 387-398.

15 L. Siracusa, T. Kulisic-Bilusic, O. Politeo, I. Krause, B. Dejanovic and G. Ruberto, J. Agric. Food Chem., 2011, 59, 12453-12459.

16 P. C. Wootton-Beard, A. Moran and L. Ryan, Food Res. Int., 2011, 44, 217-224.

17 G.-L. Chen, S.-G. Chen, Y.-Y. Zhao, C.-X. Luo, J. Li and Y.-Q. Gao, Ind. Crops Prod., 2014, 57, 150-157.

18 G. L. Chen, K. Hu, N. J. Zhong, J. Guo, Y. S. Gong, X. T. Deng, Y. S. Huang, D. K. Chu and Y. Q. Gao, Eur. Food Res. Technol., 2013, 236, 303-310.

19 N. Jayawardena, M. I. Watawana and V. Y. Waisundara, J. Verbraucherschutz Lebensmittelsicherh., 2015, 10, 349-357.

20 R. Lucas-Gonzalez, S. Navarro-Coves, J. A. Pérez-Álvarez, J. Fernández-López, L. A. Muñoz and M. Viuda-Martos, Ind. Crops Prod., 2016, 94, 774-782.

21 G. J. McDougall, P. Dobson, P. Smith, A. Blake and D. Stewart, J. Agric. Food Chem., 2005, 53, 5896-5904. 
22 L. T. Coles, P. J. Moughan and A. J. Darragh, Anim. Feed Sci. Technol., 2005, 123-124, 421-444.

23 F. Saura-Calixto, J. Serrano and I. Goñi, Food Chem., 2007, 101, 492-501.

24 M. S. Gião, S. Gomes, A. R. Madureira, A. Faria, D. Pestana, C. Calhau, M. E. Pintado, I. Azevedo and F. X. Malcata, Food Chem., 2012, 131, 761-767.

25 T. Swain and W. E. Hillis, J. Sci. Food Agric., 1959, 10, 6368.

26 A. Gordon, E. Jungfer, B. A. Da Silva, J. G. S. Maia and F. Marx, J. Agric. Food Chem., 2011, 59, 7688-7699.

27 P. Ercan and S. N. El, Food Chem., 2016, 205, 163-169.

28 N. Ortega, A. Macià, M.-P. Romero, J. Reguant and M.-J. Motilva, Food Chem., 2011, 124, 65-71.

29 A. González-Sarrías, R. García-Villalba, M. A. NúñezSánchez, J. Tomé-Carneiro, P. Zafrilla, J. Mulero, F. A. Tomás-Barberán and J. C. Espín, J. Funct. Foods, 2015, 19, 225-235.

30 S. J. Lee, S. Y. Lee, M. S. Chung and S. J. Hur, J. Funct. Foods, 2016, 22, 113-121.

31 E. Celep, M. Charehsaz, S. Akyüz, E. T. Acar and E. Yesilada, Food Res. Int., 2015, 78, 209-215.
32 B. Gullon, M. E. Pintado, J. Fernández-López, J. A. PérezÁlvarez and M. Viuda-Martos, J. Funct. Foods, 2015, 19(Part A), 617-628.

33 P. Xiao, H. Huang, J. Chen and X. Li, J. Ethnopharmacol., 2014, 157, 55-61.

34 Y. H. Wong, C. P. Tan, K. Long and K. L. Nyam, Czech J. Food Sci., 2014, 32, 177-181.

35 A. Tuominen and T. Sundman, Phytochem. Anal., 2013, 24, 424-435.

36 A. Bellesia, E. Verzelloni and D. Tagliazucchi, Int. J. Food Sci. Nutr., 2015, 66, 85-92.

37 H. Bergmann, D. Rogoll, W. Scheppach, R. Melcher and E. Richling, Mol. Nutr. Food Res., 2009, 53, 1211-1225.

38 R. Nagai, M. Nagai, S. Shimasaki, J. W. Baynes and Y. Fujiwara, Biochem. Biophys. Res. Commun., 2010, 393, 118-122.

39 N. I. Kashchenko, K. K. Chirikova and D. N. Olennikov, Molecules, 2017, 22, 73.

40 F. Jiménez-Aspee, C. Theoduloz, M. P. C. Soriano, M. Ugalde-Arbizu, M. R. Alberto, I. C. Zampini, M. I. Isla, M. J. Simirgiotis and G. Schmeda-Hirschmann, Molecules, 2017, 22, 1565. 